\title{
Synthesis of Zinc Oxide Nanoparticles and Setariaverticillata Assisted Activated Carbon Blended Zinc Oxide Nanoparticles
}

\author{
V. Raja ${ }^{1 *}$, G. Selvan', R. Anbarasu' and S. Baskar² \\ IPG and Research Department of Physics, Thanthai Hans Roever College (Autonomous), Perambalur - 621212, Tamil \\ Nadu, India; pirithishraja@gmail.com, selvan96@rediffmail.com, anbarasu.try102@gmail.com \\ 2Department of Physics, Paavendhar college of Arts and Science, Manivilundan, Attur, Salem - 636112, Tamil Nadu, \\ India; sivabaskar85@gmail.com
}

\begin{abstract}
Objectives: In this work Setariaverticillata leaf extract was utilized as bioreductant to synthesise Zinc oxide nanoparticles (ZnO-NPs) blended with activated carbon for possible application in electrochemical energy conversion systems. Methods/ Statistical Analysis: Synthesised ZnO-NPs were subjected to various physical characterization techniques. As well as the electrochemical behaviour of the Setariaverticillata activated carbon (SVAC) and nanostructured ZnO composite mixture was studied electrochemical impedance spectroscopy with $0.1 \mathrm{M} \mathrm{Na}_{2} \mathrm{SO}_{4}$ electrolyte. Findings: Wurtzite (hexagonal) form of the herb assisted synthesised ZnO-NPs with particles disseminated within the extend of 40-110 nm. The prepared ACZnOnanocomposite electrode exhibits specific capacitance of $264.8 \mathrm{~F} / \mathrm{cm}^{2}$ at $5 \mathrm{mV} / \mathrm{s}$ scan rate. The specific capacitance of the electrodes diminished with increment in zinc oxide substance. The improved electrochemical behaviour of the nanocomposite can be credited to the high electrical conductivity of the activated carbon and electro active. Application/ Improvements: ZnO Setaria assisted activated carbon-ZnOnanocomposite was prepared as a perspective candidate to exhibit its applicability as active materials for electrochemical energy conversion such as super capacitors.
\end{abstract}

Keywords: AC-ZnOnanocomposite, Nanomaterial, Supercapacitor, Specific Conductance, ZnO

\section{Introduction}

Nanotechnology is developed as a modern field of research dealing with synthesis of nanoparticles and their applications in different areas such as photocatalysis, biomedicines, electrochemistry, sensors, pharmaceutics, well being care, beauty care products, nourishment innovation, textile industry, energy science, optical devices, etc ${ }^{1-3}$. Surface morphology of the nanoparticles plays a crucial part in different applications. Semiconductor nanoparticles has gained attention in the current scenario because they have better possibilities in optoelectronics and bioapplications ${ }^{4,5}$. Among the various semiconductor nanoparticles, $\mathrm{ZnO}$ has received considerable attention because of its unique property of having high excitation binding energy of $60 \mathrm{meV}^{\underline{6}}$ and band gap of $3.3 \mathrm{eV}^{\underline{7}}$. ZnO-NPs are being synthesised throughvarious physical and chemical methods which includes wet chemical route ${ }^{8}$, vapour phase process ${ }^{9}$, hydrothermal ${ }^{10}$, precipitation ${ }^{11}$ sonochemical methods etc. However,these methods involvethe usage of toxic chemicals, expensive instruments and tedious process. Therefore, development of inexpensive and green strategy to synthesis $\mathrm{ZnO}-\mathrm{NPs}$ is really demanding. Bio-inspired $\mathrm{ZnO}-\mathrm{NPs}$ has pulled in significant consideration due to its effortlessness, inexpensive and non-toxicity. Demand for simple and secure green strategy in scale up and mechanical production of well scattered metal nanoparticles, plant extracts are considered as amazing availablebioresource $e^{12-14}$.

${ }^{*}$ Author for correspondence 
Due to the restricted accessibility of fossil fuel and its associated drawbacks of worldwide warming and natural contamination. Current research focuses on the development of renewable energy resources along with eco-friendly technology for energy conversion and storage ${ }^{15,16}$. Supercapacitors are also known as electrochemical capacitors which finds wide applications because of high power density, natural invitingness, long life time and long shelf life ${ }^{17,18}$. Much of the research has been carried out to increase the overall performance of the super capacitors. $\mathrm{ZnO}$ is an important battery active material with the battery density of $650 \mathrm{~A} / \mathrm{g}$, eco-friendly in nature and promising electrode for super capacitorapplications ${ }^{19}$. In this work, bioinspired $\mathrm{ZnO}$-NPswas synthesized utilizing Setariaverticillate as bioreductant. Activated carbon-ZnOnanocomposite electrode has been prepared as a potential candidate for fabrication of super capacitors and electrochemical properties was evaluated by using electrochemical impedance spectroscopy.

\section{Experimental}

\subsection{Preparation of Setariaverticillata Leaf Extract (SVLE)}

Setariaverticillata leaves were gathered and utilized for the preparation of aqueous leaf extract of Setariaverticillata. The collected leaves were washed well with deionised water and remove grime particles and then chop into small pieces. The freshly chop leaf pieces $(40 \mathrm{~g})$ was boiled with $400 \mathrm{ml}$ deionized water and boiled at $90^{\circ} \mathrm{C}$ for 0.17 hour.The obtained crude extract was cooled in wellventilated area (approximately $28^{\circ} \mathrm{C}$ ), filtered through Whatmann filter and refrigerated for further use.

\subsection{Eco-Friendly Synthesis of Zinc Oxide Nanoparticles}

The white, crystalline Zinc nitrate was acquired from S.D.Fine chemicals (Bangalore, India). The fresh herb extract was added with $10 \mathrm{mM} \mathrm{Zn}\left(\mathrm{NO}_{3}\right)_{2}$ solution in a $\mathrm{RB}$ flask at ambient temperature for $6 \mathrm{~h}$. The pale-yellow colour solution thus obtained was dried at $100^{\circ} \mathrm{C}$ in hotair oven. The resultant mass obtained was subjected to calcination at $400{ }^{\circ} \mathrm{C}$ to get fine solid of $\mathrm{ZnO}$-NPs and kept in air free containers. Green approach of formation of Setaria mediated $\mathrm{ZnO}-\mathrm{NPs}$ is shown in Figure 1.

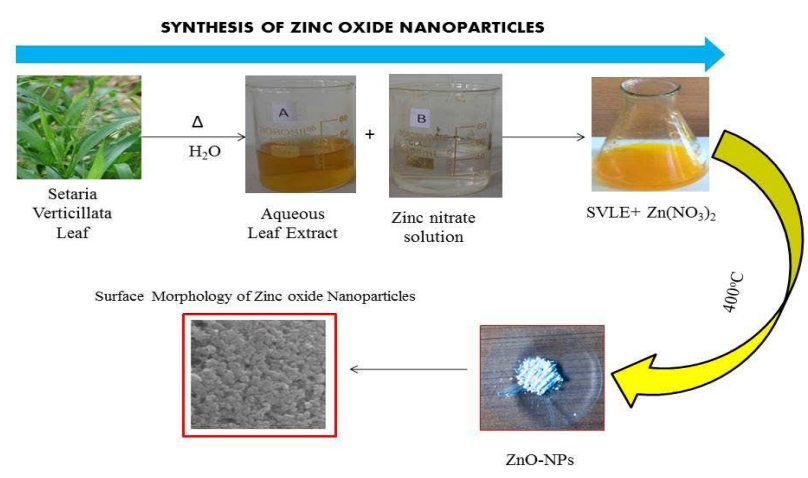

Figure 1. Schematic synthetic route of Zinc oxide nanoparticles.

\subsection{Preparation of Setariaverticillata Activated Carbon (SVAC)}

Setariaverticillataleaves were first washed a few times with demineralized water to expelresidue, soil and suspended impurities. The material is grounded by using pestle and mortar to turn it into fineparticles. About $100 \mathrm{~g}$ of powdered fine materials was blended with $0.05 \mathrm{~L}$ of conc. $\mathrm{H}_{2} \mathrm{SO}_{4}$ and kept at room temperature for $24 \mathrm{~h}$. Then washed with double distilled water to remove excess of acid and dried at $110^{\circ} \mathrm{C}$ for $14 \mathrm{~h}$ to remove moisture and stored in dry atmosphere.

\subsection{Preparation of AC-ZnO Electrode}

Activated carbon was blended with $\mathrm{ZnO}$ in three distinct proportions $\{2: 0.5,2: 3,2: 2,2: 1\}$ by utilizing $n$-methyl pyrrolidone along with binding agent, polyvinylidiene fluoride and made into a paste. After that, the paste AC- $\mathrm{ZnO}$ composite was applied with a brush on weighed stainless steel current collector and dried at $25^{\circ} \mathrm{C}$.

\subsection{Electrochemical Characterisation of Electrode}

Electrochemical impedance measurements were performedin $0.01 \mathrm{~L}$ of $100 \mathrm{mM} \mathrm{Na}_{2} \mathrm{SO}_{4}$ electrolyte over a potential range of $-0.9 \mathrm{~V}$ to $+0.1 \mathrm{~V}$, the solution was employed as the experimental solution for $\mathrm{ZnO}$ nanoparticles. Electrochemical Impedance Spectroscopy (EIS) of the nanoparticle modified electrodes was measured in $100 \mathrm{mM} \mathrm{Na}_{2} \mathrm{SO}_{4}$ at perturbation amplitude of $0.01 \mathrm{~V}$ within a frequency range of $0.0001 \mathrm{mHz}$ to $100 \mathrm{mHz}$. 


\subsection{Characterisation of Setaria Mediated $\mathrm{ZnO}-\mathrm{NPs}$}

UV-1601 Shimadzu spectrophotometer is utilized to record UV-Vis spectra which were confirmed the formation of ZnO-NPs. Functional groups of Setaria verticillata and bio synthesised ZnO-NPs analysed by FT-IR spectra with the help of BRUKER-FTIR-TENSOR-27 spectrophotometer instrument. The size, shape and elemental composition of bio-synthesised $\mathrm{ZnO}-\mathrm{NPs}$ were investigated by using SEM, Hitachi S4700, equipped with Energy Dispersive Spectroscopy (EDS). The phase identification of bio-synthesised $\mathrm{ZnO}$-NPs analyzed with $\mathrm{X}$-ray diffractometer (PANanalytical X-Pert PRO).

\section{Results and Discussion}

\subsection{Characterization of Bio-Synthesised $\mathrm{ZnO}-\mathrm{NPs}$}

UV-Vis spectral technique is an important role in anticipating the formation of metal oxide nanoparticles. Absorption spectrum of the Setaria verticillata leaf extract, Setaria verticillata associated with Zinc Nitrate and biosynthesized $\mathrm{ZnO}$ nanoparticles is depicted in Figure 2.

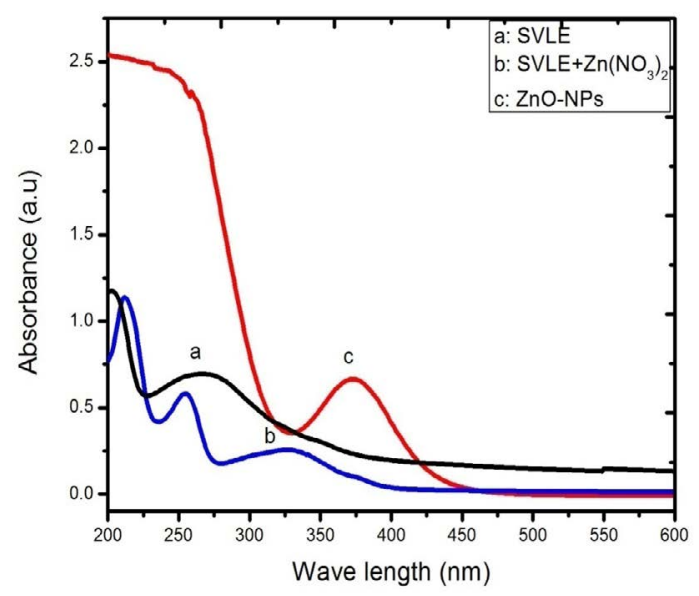

Figure 2. (a) The UV-visible spectrum of Setariaverticillata leaf extract. (b) Setariaverticillata leaf extract with zinc nitrate. (c) ZnO-NPs.

From the figure, it is confirmed that Surface Plasmon Resonance (SPR) band for $\mathrm{ZnO}$ nanoparticles due to the absorption peak occurred at $376 \mathrm{~nm}^{20}$. This is inagreement with the reported work on the eco-friendly synthesis of $\mathrm{ZnO}$-NPs (absorption peak at $374 \mathrm{~nm}$ ) utilizing various herb extracts $\frac{21,22}{2}$, which affirmed the presence of $\mathrm{ZnO}$ nanoparticles.

Figure 3(a), (b), FT-IR spectra of the Setariaverticillata leaf extract and synthesised ZnO-NPs. FT-IR spectra of the Setariaverticillata spectra reveals many absorption peaks at $1060,1402,1625,2350,2926,3400 \mathrm{~cm}^{-1}$ together with other tiny peaks. These bands relate to $\mathrm{C}-\mathrm{H}$ bending modes within the organic compound chains, $\mathrm{C}-\mathrm{H}$ bend of alkynes and $\mathrm{C}-\mathrm{O}$ stretching, $\mathrm{C}-\mathrm{OH}$ stretching vibrations, $\mathrm{C}=\mathrm{C}$ stretching, $\mathrm{C}=\mathrm{O}$ group, $-\mathrm{OH}$ and/or $-\mathrm{NH}$ stretching vibrations. A wide peak due to $-\mathrm{OH}$ band is observed at $3450 \mathrm{~cm}^{-1}$. A weak absorption peaks at $2922 \mathrm{~cm}^{-1}$ and $2852 \mathrm{~cm}^{-1}$ are due to aliphatic asymmetric C-H stretching vibrations and carboxylic acids stretching $-\mathrm{C}-\mathrm{H}$. The peak at $1745 \mathrm{~cm}^{-1}$ corresponds to $\mathrm{C}=\mathrm{O}$ stretching vibrations of carbonyl group. The weak absorptionpeaks at $1164 \mathrm{~cm}^{-1}$ and $1322 \mathrm{~cm}^{-1}$ are indicative of $\mathrm{C}=\mathrm{N}$ stretching of amide bonds. In addition, $\mathrm{C}-\mathrm{O}-\mathrm{C}$ stretching vibrationscoincide with the absorption peak at $1020 \mathrm{~cm}^{-1}$. The crest at $744 \mathrm{~cm}^{-1}$ is due to existence of $\mathrm{R}-\mathrm{CH}$ group and peak at $669 \mathrm{~cm}^{-1}$ demonstrates the vibration band of $\mathrm{ZnO}-\mathrm{NPs}$ according to the data recordeddistinctivepeak at $490 \mathrm{~cm}^{-1}$ can be ascribed to the [Zn-O] bond of metal oxygen ${ }^{23,24}$.

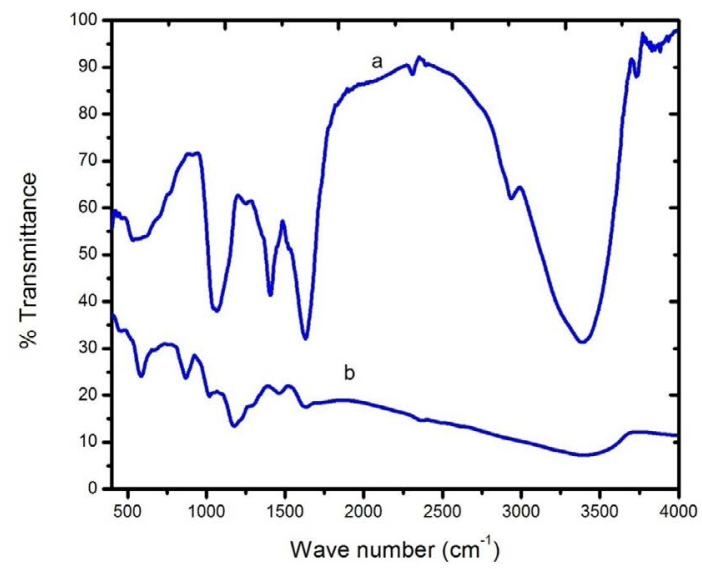

Figure 3. (a) The FT-IR spectrum of SVLE. (b) SetariamediatedZnO-NPs.

Figure 4(a) indicates that synthesised $\mathrm{ZnO}-\mathrm{NPs}$ have ball shape and particle dimension varies between 40-110 
nm.The EDX spectrum of eco-friendly synthesised $\mathrm{ZnO}$ NPs as displayed in Figure 4(c) reveals the chemical characterization of $\mathrm{ZnO}-\mathrm{NPs}$ and high purity of $\mathrm{ZnO}$ NPs except impurities. Scanning electron microscopy was used to assign the shape, size and morphology of activated carbon prepared from Setariaverticillata leaves (Figure 4(b)). Figure 4(b) confirms the particle size in the range of 8-10 nm. Further confirmation of prepared activated carbon was done by Energy Dispersive X-ray analysis (EDX). Figure 4(d) for the activated carbon showed two characteristic signals for $\mathrm{C}$ and $\mathrm{O}$ composition as $73.52 \%, 26.48 \%$ respectively.
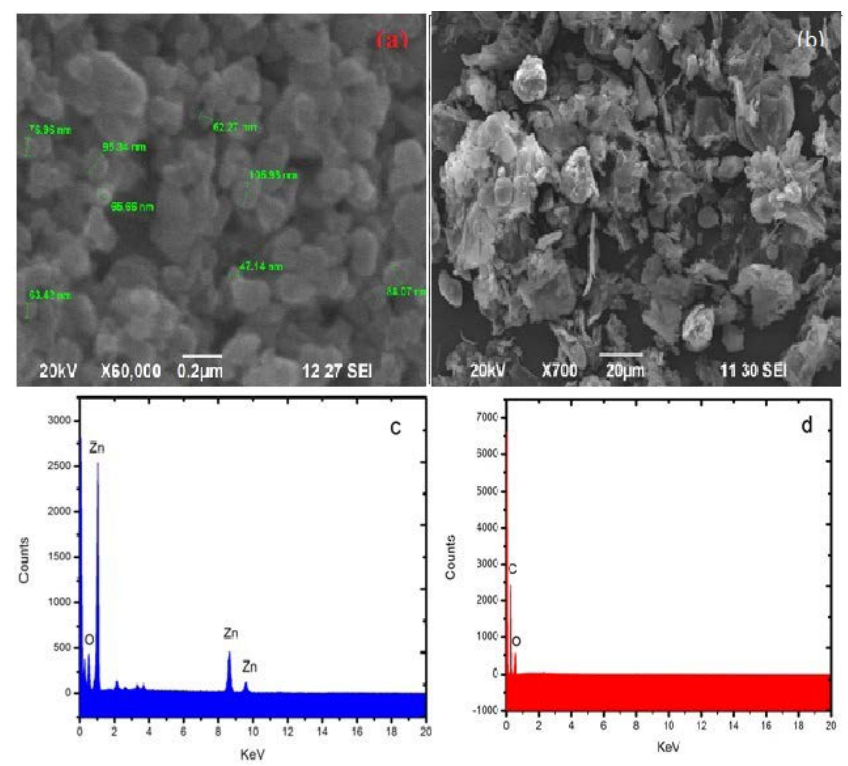

Figure 4. (a) SEM image of ZnO-NPs. (b) SEM image of Activated carbon prepared from Setariaverticillata Leaves. (c) EDX spectra of pure ZnO-NPs. (d) EDX spectra of activated carbon.

The XRD analysis of the Setaria mediated Zinc oxide nanoparticles reveals the chemical composition, physical properties and crystallographic structure of the $\mathrm{ZnO}$ NPs (Figure 5(a)). The obtained diffraction peaks at 31.9, $34.8,36.8,47.5,56.3,62.9,68.1,69.2$ and 77.0 as shown in Figure 5(a) corresponds to miller indices of 100, 002, 10 $1,102,110,103,112,201$ and 202 planes respectively. The got outcomes were in appropriate agreement with JCPDS file No. 036-1451 confirming the hexagonal wurtzite structure $^{25}$. The clear severe peak bought suggests the excessive purity and crystalline nature of the synthesised ZnO-NPs. No differentdiffraction peaks are recognized suggesting purity of the synthesized ZnO-NPs. Figure 5(b) displays XRD pattern of activated carbon. The characteristics $10-30^{\circ}$ peaks of SVAC were discernible in carbon, the obtained diffraction spectrum did not show any obvious peak at the scan range $10-90^{\circ}$ thereby indicating the amorphous phase of SVAC.
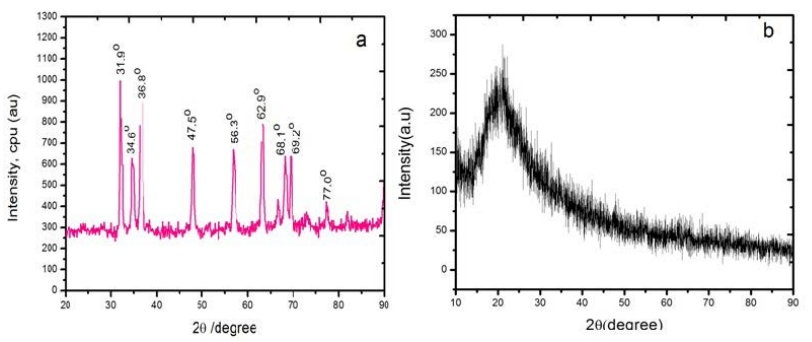

Figure 5. (a) XRD patterns of SetariamediatedZnO-NPs. (b) XRD spectrum of activated carbon.

\subsection{Electrochemical Properties of AC- $\mathrm{ZnO}$ Composite and Supercapacitors}

AC-ZnOnanocomposite electrodes was prepared with various composition ratios such as 2:0.5, 2:1, 2:2 and 2:3 prepared on stainless steel panels. Figure 6 shows the Nyquistplots for the AC-ZnOnanocomposite having different compositions in the ratios 2:1, 2:2 and 2:3. The specific capacitance calculation shows that composite composition in the ratio 2:0.5 has highest specific conductance as shown in Table 1. Figure 7 shows the Nyquist plot for nanocomposite electrode with 2:0.5 composition which exhibits lowest resistance and higher specific capacitance. The improved electrochemical performance of AC-ZnOnanocomposite can be attributed to the electro active property of ZnOsupported on activated carbon provides a three-dimensional conducting system which givesactive sites for the formation of electrical double layer ${ }^{26}$ and pseudo capacitance from the $\mathrm{ZnO}$ provides a higher specific capacitance ${ }^{27,28}$.

Table 1. Electrochemical Impedance parameters for AC-ZnO electrode in $0.1 \mathrm{M} \mathrm{Na}_{2} \mathrm{SO}_{4}$

\begin{tabular}{|l|l|l|l|}
\hline Materials & $\begin{array}{l}\text { Scan rate } \\
(\mathrm{mV} / \mathrm{Sec})\end{array}$ & $\begin{array}{l}\text { Charge } \\
\text { transfer } \\
\text { resistance } \\
\left(\mathrm{cm}^{2}\right)\end{array}$ & $\begin{array}{l}\text { Capacitance } \\
\left(\mathrm{F} / \mathrm{cm}^{2}\right)\end{array}$ \\
\hline AC-ZnO (2:3) & 5 & 4.1 & 2.5 \\
\hline AC-ZnO (2:2) & 5 & 40.3 & 30.5 \\
\hline AC-ZnO (2:1) & 5 & 59.2 & 57.4 \\
\hline AC-ZnO (2:0.5) & 5 & 1602.0 & 264.8 \\
\hline
\end{tabular}




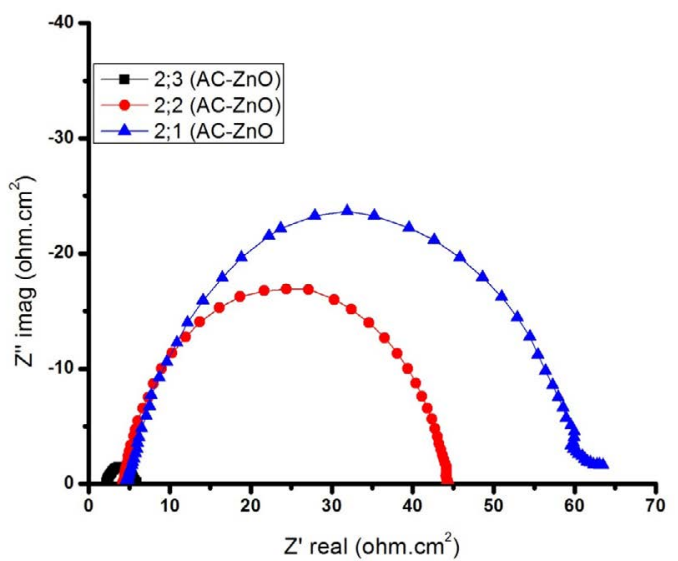

Figure 6. Impedance plots for $\mathrm{AC}-\mathrm{ZnO}$ composites at compositions of 2:3, 2:2 and 2:1.

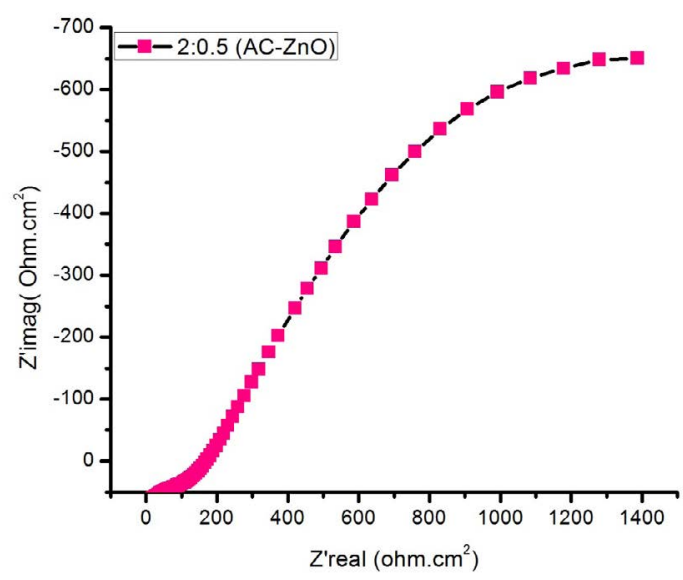

Figure 7. Impedance plots for AC- $\mathrm{ZnO}$ composites at 2:0.5 mass ratio.

\section{Conclusion}

In the present work, we report the nanostructured $\mathrm{ZnO}$ has been prepared by using Setariaverticillata as bioreductant. Biosynthesised $\mathrm{ZnO}$-NPs acted as super capacitor by using composting with activated carbon. Super capacitor was fabricated by using the composite electrodes and studied for electrochemical properties using electrochemical impedance spectroscopy. The studies reveal that super capacitor has good capacitance and can be used as a super capacitor active material.

\section{References}

1. Huanga NM, Limb HN, Radimanc S, Khiewd PS, Chiud WS, Hashime R, Chiac CH. Sucrose ester micellar-mediated synthesis of $\mathrm{Ag}$ nanoparticles and the antibacterial properties. Colloids and Surfaces A: Physicochemical and Engineering Aspects. 2010; 353:69-76. https://doi. org/10.1016/j.colsurfa.2009.10.023

2. Nel A, Xia T, Madler L, Li N. Toxic potential of materials at the nanolevel. Science. 2006; 311:622-7. https://doi. org/10.1126/science.1114397 PMid:16456071

3. Amornpitoksuk P, Suwanboon S, Sangkanu S, Sukhoom A, Wudtipan J, Srijan K, Kaewtaro S. Synthesis, photocatalytic and antibacterial activities of $\mathrm{ZnO}$ particles modified by diblock copolymer. Powder Technology. 2011; 212:432-8. https://doi.org/10.1016/j.powtec.2011.06.028

4. Konenkamp R, Dloczik L, Ernst K, Olecsh C. Nanostructures for solar cells with extremely thin absorbers. Physica E: Low-dimensional systems and Nanostructures. 2002; 14:219-23. https://doi.org/10.1016/S13869477(02)00387-9

5. Vayssieres L, Keis K, Hagfeldt A, Lindquist SE. Three dimensional array of highly oriented crystalline ZnOMicrotubes. Chemistry of Materials. 2001; 13:4395-8. https://doi. org/10.1021/cm011160s

6. Yilmaz S, Nisar J, Atasoy Y, McGlynn E, Ahuja R, Paralak, Bacaksiz E, Defect induced room temperature ferromagnetism in B-doped ZnO. Ceramics International. 2013; 39:4609-17. https://doi.org/10.1016/j.ceramint.2012.11.060

7. Suwanboon S, Amornpitoksuk P, Sukolrat A, Muensit N. Optical and photocatalytic properties of La-doped $\mathrm{ZnO}$ nanoparticles prepared via precipitation and mechanical milling method. Ceramics International. 2013; 39:2811-9. https://doi.org/10.1016/j.ceramint.2012.09.050

8. Taunk PB, Das R, Bisen DP, Tamrakar RK. Structural characterization and photoluminescence properties of zinc oxide nanoparticles synthesized bychemical route method. Journal of Radiation Research and Applied Sciences. 2015; 8:433-8. https://doi.org/10.1016/j.jrras.2015.03.006

9. Kolekar TV, Bandgar SS, Shirguppikar SS, Ganachari VS. Synthesis and characterization of $\mathrm{ZnO}$ nanoparticles for efficient gas sensors. Archives of Applied Science Research. 2013; 5:20-8.

10. Balantrapu K, Goia D. Silver nanoparticles for printable electronics and biological applications. Journal of Materials Research. 2009; 24:2828-36. https://doi.org/10.1557/ jmr.2009.0336

11. Tripathi RM, Saxena A, Gupta N, Kapoor H, Singh RP. High antibacterial activity of silver nanoballs against $\mathrm{E}$. 
coli MTCC 1302, S. typhimurium, MTCC 1254, B. subtilis MTCC 1133 and P. aeruginosa MTCC 229. Digest Journal of Nanomaterials and Biostructures. 2010; 5:323-30.

12. Sundrarajan M, Ambika S, Bharathi K. Plant-extract mediated synthesis of $\mathrm{ZnO}$ nanoparticles using Pongamiapinnata and their activity against pathogenic bacteria. Advanced Powder Technology. 2015; 26:1294-99. https://doi.org/10.1016/j.apt.2015.07.001

13. Jeevanandam J, Chan YS, Danquah MK. Biosynthesis of metal and metal oxide nanoparticles. ChemBioEng Reviews. 2016; 3:55-67. https://doi.org/10.1002/cben.201500018

14. ShankerU, Jassal V, Rani M, Kaith BS. Towards green synthesis of nanoparticles, from bio-assisted sources to benign solvents. A review. International Journal of Environmental Analytical Chemistry. 2016; 96:801-35.

15. Wang G, Zhang L, Zhang J. A review of electrode materials for electrochemical Super capacitors. Chemical Society Reviews. 2012; 41:797-828. https://doi.org/10.1039/ C1CS15060J PMid:21779609

16. Bose S, Kuila T, Mishra AK, Rajasekar R, Kim NH, Lee JH. Carbon based Nanostructured materials and their composites as super-capacitor electrodes. Journal of Materials Chemistry. 2012; 22:767-84. https://doi.org/10.1039/ C1JM14468E

17. Wang J, Gao Z, Li Z, Wang B, Yan Y, Liu Q, Mann T, Zhang $M$, Jiang $Z$. Green synthesis of grapheme nano sheets/ZnO composites and electrochemical properties. Journal of Solid State Chemistry. 2011; 184:1421-7. https://doi.org/10.1016/j.jssc.2011.03.006

18. Baker J. New technology and possible advances in energy storage. Energy Policy. 2008; 36:4368-73. https://doi. org/10.1016/j.enpol.2008.09.040

19. Selvakumar M, Bhat DK, Aggarwal AM, Iyer SP, Sravani G. Nano ZnO-activated carbon composite electrodes for super capacitors. Physica B. 2010; 405:2286-9. https://doi. org/10.1016/j.physb.2010.02.028

20. Kanagamani K, Muthukrishnan P, Saravanakumar K, Shankar K, Kathiresan A, Photocatalytic degradation of environmental perilous gentian violet dye using Leucaenamediated zinc oxide nanoparticle and its anticancer activity. Rare metals. 2019; 38:277-86. https://doi.org/10.1007/ s12598-018-1189-5
21. Bhuyan T, MishraK, Khanuja M, Prasad R, Varma A. Biosynthesis of zinc oxide nanoparticles from Azadirachtaindica for antibacterial and photocatalytic applications. Materials Science in Semiconductor Processing. 2015; 32:55-61. https://doi.org/10.1016/j.mssp.2014.12.053

22. Sangeethaa G, Rajeshwari S, Venckatesh R. Green synthesis of zinc oxide nanoparticles by aloebarbadensis miller leaf extract Structure and optical properties. Mater Res Bull. 2011; 46:2560-6. https://doi.org/10.1016/j.materresbull.2011.07.046

23. Abdul Salam H, Sivaraj R, Venckatesh R. Green synthesis and characterization of zinc oxide nanoparticles from Ocimumbasilicum L. var. purpurascens Benth.-Lamiaceae leaf extract. Materials Letters. 2014; 131:16-8. https://doi. org/10.1016/j.matlet.2014.05.033

24. Azizia S, Ahmada MB, Namvarb F, Mohama R, Green biosynthesis and characterization of zinc oxide nanoparticles using brown marine macroalga Sargassummuticum aqueous extract. Materials Letters. 2014; 116:275-7. https://doi. org/10.1016/j.matlet.2013.11.038

25. Vanathi P, Rajiv P, Narendhran S, Rajeshwari S, Rahman PKSM, Venckatesh R. Biosynthesis and characterization of phytomediated zinc oxidenanoparticles- A green chemistry approach. Materials Letters. 2014; 134:13-5. https://doi. org/10.1016/j.matlet.2014.07.029

26. Li Z, Liu P, Yun G, Shi K, Lv X, Li K, Xing J, Yang B. 3D (Three dimensional) sandwich structured of $\mathrm{ZnO}$ (zinc oxide)/rGO (reduced grapheme oxide)/ZnO for high Performance supercapacitors. Energy. 2014; 69:266-71. https://doi.org/10.1016/j.energy.2014.03.003

27. Hsieh CT, Lin JS, Chen YF, Lin CY, Li WY. Graphene sheets anchored with $\mathrm{ZnO}$ nanocrystals as electrode materials for electrochemical capacitors. Materials Chemistry and Physics. 2014; 143:853-9. https://doi.org/10.1016/j. matchemphys.2013.10.024

28. Zhang Y, Li H, Pan L, Lu T,Sun Z. Capacitive behaviour of grapheme-ZnO composite film for supercapacitors. Journal of Electroanalytical Chemistry. 2009; 634:68-71. https:// doi.org/10.1016/j.jelechem.2009.07.010 